\title{
O DIREITO DE RECUSA À APLICAÇÃO DE VACINAS: A LIBERDADE VERSUS O DIREITO À VIDA E À SAÚDE
}

\author{
Deise Santos Curt ${ }^{1}$ \\ Luis Filipe Fernandes Ferreira ${ }^{2}$
}

\section{Resumo:}

A taxa de cobertura vacinal do Programa Nacional de Imunizações vem caindo nos últimos anos afetando o combate à Covid-19, trazendo de volta a doenças já erradicadas e diminuindo a expectativa de vida nacional. Este artigo busca analisar a correlação entre a queda da vacinação e a disseminação de fake News contrárias à vacinação; e analisar o conflito entre o direito individual de não se vacinar (direito à liberdade) versus o direito coletivo à vida (direito à vida) para identificar qual direito deve prevalecer. Foi usado o método dedutivo, com pesquisa de doutrina, jurisprudência, legislação pátria, dados estatísticos e históricos.

Palavras-chave: antivacinas, fake news, direitos fundamentais, direito à vida, direito à liberdade.

\section{THE RIGHT OF REFUSAL TO APPLICATION OF VACCINES: THE FREEDOM VERSUS THE RIGHT TO LIFE AND HEALTH}

\begin{abstract}
:
The vaccination coverage rate of the National Immunization Program has been falling in recent years, affecting the fight against Covid-19, bringing back diseases that have already been eradicated and reducing national life expectation. This article seeks to analyze the correlation between that fall in vaccination and the fake News dissemination against vaccination; and analyze the conflict between the individual right not to be vaccinated (right to freedom) versus the collective right to life (right to life) to identify which one should prevail. The deductive method was used, with research on doctrine, jurisprudence, national legislation, statistical and historical data.
\end{abstract}

Keywords: antivaccines, fake news, fundamental rights, right to freedom, Right to life.

\section{INTRODUÇÃO}

Desde 2016, a taxa de cobertura das vacinas constantes no calendário vacinal do país vem sofrendo queda, graças ao movimento anti-vacinas que cresce exponencialmente no mundo, principalmente nos Estados Unidos e Brasil. O Brasil, chegou a ter em suas campanhas nacionais de imunização, taxas de cobertura entre 95 a 100\%, em todo o território

\footnotetext{
${ }^{1}$ Advogada, especialista em direito médico e da saúde, especialista em direito empresarial. Atuante nas áreas: cível, família e sucessões e em direito médico e da saúde

${ }^{2}$ Mestre em Direito da Sociedade da Informação(FMU-SP); Especialista: Direito de Família (IBMEC/Damásio); Bacharel: Direito (UNIP); Advogado; MBA: Gestão Empresarial (FGV-SP); Especialista: Sistemas de Informação (Mackenzie); Analista de Sistemas pela FATEC-SP.
} 
nacional.

Inicialmente, o programa de vacinação no país gerava desconfiança na população, como se verá adiante, por conta da pouca informação fornecida pelo governo, a compulsoriedade da vacinação contra as doenças que assolavam e matavam milhares de brasileiros, a arbitrariedade dos agentes de saúde para realizar os procedimentos, somados à alta incidência da disseminação de falsas informações acerca da efetividade das vacinas, resultou na chamada Revolta da Vacina. O Programa Nacional de Imunizações, como existe hoje, foi sofrendo transformações até se tornar modelo de sucesso no país, ao ponto de erradicar doenças como o sarampo e a paralisia infantil.

Atualmente, o excesso de informações na rede poderia cooperar com a disseminação da informação sobre todos os segmentos, porém, o que ocorre é justamente o contrário: o excesso de informação, somado à nova característica da pós-modernidade, qual seja, o hedonismo, aliados à uma nova sociedade da rede, que forma grupos e bolhas virtuais, faz com que esses grupos de indivíduos se agrupem para reafirmar suas concepções pessoais, com fake News ou não, escolhendo acreditar no que querem.

Desse modo, esses grupos, fechados em suas bolhas, acreditam no que preferem acreditar, tendo como verdade a "sua própria verdade". O excesso de informação enseja a desinformação e fomenta grupos anti-vacinas, que faz com que doenças que, antes estavam erradicadas, retornem. Além disso, há uma epidemia mundial, de Covid-19, que mata pessoas no mundo todo.

Em outubro de 2020, já há diversas vacinas desenvolvidas no mundo todo e que estão sendo distribuídas para a população, porém, a adesão da população, gerada pela desconfiança perpetrada dentre os grupos anti-vacinas, é bem aquém do desejado e está influenciando, também na adesão da vacinação contra outras doenças já incluídas no calendário vacinal e que tinham quase, ou senão, a totalidade da adesão da população.

Uma das formas sugeridas para que haja estímulo da adesão às vacinas contra a covid 19, é a instituição de uma espécie de "passaporte da vacina". Este seria um documento a ser apresentado pelas pessoas que quisessem permanecer em locais com aglomeração de pessoas, como shoppings, casas de shows, restaurantes etc., que atestasse que a pessoa está imunizada contra a covid-19.

Por conta disso, grupos voltaram a discutir o direito fundamental de liberdade de escolha de não se vacinar, sem que haja o impedimento de acesso aos lugares que pretendem ir e permanecer. 
Do outro lado, há pessoas que desejam der a liberdade de permanecer nos estabelecimentos, sem que coloquem em risco a sua saúde por estarem perto de pessoas potencialmente mais propensas a disseminar a doença por não estarem imunizadas, defendendo o direito à liberdade mediante este "cartão de acesso", ou seja, liberdade mediante a limitação imposta pelo poder público com a garantia do direito à vida.

Desse modo, o judiciário atua como ente balizador desses direitos fundamentais, liberdade versus o direito à vida, o que gera bastante discussão e revolta entre grupos, que se socorrem dos mesmos dispositivos legais para defender seus interesses, além de disseminação de seus ideais em canais midiáticos que estão em consonância com seus interesses.

Este artigo busca disseminar informações sobre dados objetivos e comparativos entre os resultados das campanhas de imunização para a saúde e expectativa de vida da população e, por fim, demonstrar qual direito fundamental deve prevalecer em relação ao passaporte da vacina, através do método dedutivo, com pesquisa de doutrina, jurisprudência, as leis, dados estatísticos, históricos e discussões sociológicas e filosóficas, para se concluir qual direito fundamental deve prevalecer: o direito à vida ou o direito à liberdade.

\section{A REVOLTA DA VACINA E O PROGRAMA NACIONAL DE IMUNIZAÇÕES}

Em 1904, a cidade do Rio de Janeiro enfrentou grandes epidemias, incluindo mais de três mil mortos por conta da varíola. (TEIXEIRA, 2018, p. 62) Por conta disso, o médico sanitarista, Oswaldo Cruz foi nomeado Diretor da pasta da saúde pelo, até então, presidente da Republica, Rodrigues Alves, com o objetivo de combater a varíola , a febre amarela e a peste. (TEIXEIRA, 2018. p.62).

O médico adotou uma política de reforma sanitária e urbana muito polêmica, que consistia em abrir grandes avenidas e vielas, desalojar pessoas (que foram obrigadas a morarem em mangues e morros), a permissão de invasão de funcionários públicos nas residências para aplicarem, compulsoriamente, a vacina e a exigência de apresentação de atestado de vacinação para a matrícula de crianças nas escolas, admissão dos trabalhadores, para viagem e para casamento. (TEIXEIRA, 2018, p. 62)

A pouca informação acerca dos efeitos e riscos das vacinas e os vários boatos sobre o prejuízo destas circulavam livremente. Então, a pouca informação disseminada e as falsas informações difundidas livremente, aliadas ao autoritarismo dos funcionários públicos geraram uma forte reação da população às medidas governamentais, culminando na conhecida Revolta da Vacina, com confrontos que ocorreram entre 10 e 16 de novembro de 1904, 
deixando 30 mortos, 110 feridos e 9445 detidos. Essa revolta ficou conhecida como o primeiro movimento antivacina no Brasil. (TEIXEIRA, 2018, p. 62)

Para a Constituição Federal de 1988, a "saúde é um direito de todos e dever do Estado, que deverá garantir, através de políticas sociais para reduzir o risco e o agravo de doenças, dando um acesso universal e igualitário para a promoção, proteção e recuperação da saúde. Nesse caso, o art. 196 também preconiza que para garantir essas formas de promoção das políticas públicas de saúde, há um dever de solidariedade entre o ente político as pessoas, a família, as empresas e da sociedade. (BRASIL, 1988)

Assim, diversos programas de saúde foram criados a partir do Sistema Único de saúde- SUS, preconizado pelo art. 198 da Carta Magna e regido pela Lei $n^{\circ}$ 8.080/90. Para o SUS, no art. $2^{\circ}$ da lei, "A saúde é um direito fundamental do ser humano, devendo o Estado prover as condições indispensáveis ao seu pleno exercício".

E em relação ao SUS, as políticas de saúde e o dever de solidariedade, por exemplo, o Estatuto da Criança e do adolescente diz, no art. 14, que "que o SUS promoverá programas de assistência médica e odontológica para a prevenção das enfermidades que ordinariamente afetam a população infantil, e campanhas de educação sanitária para pais, educadores e alunos" e será obrigatória a vacinação nos casos recomendados pelas autoridades sanitárias.

O programa nacional de imunizações que havia sido criado em 1973, após a campanha de erradicação da varíola, foi aprimorado e mantido após a promulgação da constituição federal de 1988 e criação do SUS (TEMPORÃO, 2003, p. 602)

Inicialmente, a campanha contava com as vacinas contra a varíola, poliomielite, difteria, tétano, coqueluche, BCG e sarampo (MINISTÉRIO DA SAÚDE, 2019), com uma estratégia "campanhista", ou seja, vacinando somente as doenças que apresentavam surtos na época e em nível Estadual. (TEMPORÃO, 2003. p. 607). Atualmente, conta com a cobertura de mais de 25 doenças (MINISTÉRIO DA SAÚDE, 2019), com uma estratégia preventiva contra surtos de doenças e é realizada à nível nacional. (TEMPORÃO, 2003, p. 607)

A Faculdade de Saúde Pública de São Paulo da Universidade de São Paulo defendia que houvesse o fortalecimento da vacinação de rotina, nas unidades de saúde, e que houvesse uma maior organização de ações de vigilância epidemiológica, assim, entre 1974 e 1979, auxiliou o Governo para a reestruturação do PNI vigente, que não tinha uma estrutura de imunização a nível nacional, efetivos estudos sobre os resultados obtidos nessas campanhas e nem quantidade de profissionais especializados em imunologia suficientes para atender às demandas nacionais de pesquisa e combate às endemias, porém, mesmo assim, as campanhas 
de vacinação produziam resultados pouco satisfatórios e que confundiam a população, de modo que poderiam se tornar insustentáveis. (TEMPORÃO, 2003, pp. 607- 608)

Em 1975, foi promulgada a lei n. 6.259, trata "sobre a organização das ações de Vigilância Epidemiológica, sobre o Programa Nacional de Imunizações, estabelece normas relativas à notificação compulsória de doenças, e dá outras providências", recepcionada pela Constituição de 1988.

Esta lei, ainda vigente no país, antes da nova redação que permanece vigente no país dizia que existiam vacinas de caráter obrigatório (art. $3^{\circ}$ ), que deveriam ser comprovadas através de um atestado de vacina $\left(\operatorname{art} .5^{\circ}\right)$ e, exigia no art. $5^{\circ}, \S 3^{\circ}$ : que houvesse o pagamento de um salário-família, e apresentação do segurado a apresentação dos Atestados de Vacinação dos seus beneficiários, que comprovassem o recebimento das vacinações obrigatórias, na forma que vierem a ser estabelecidas em regulamento. (BRASIL, 1975)

Até 1974, os Estados apenas notificavam os casos; em 1975. Em 1975, foi instituído o "Sistema Nacional de Saúde e foi implantado o Sistema Nacional de Vigilância Epidemiológica (que incluiu a vigilância da poliomielite), que estabeleceu normas técnicas referentes à notificação, investigação dos casos, confirmação laboratorial e avaliação de sequelas”. (CAMPOS, 2003, p. 591). Desse modo, as doenças passaram a ter uma busca ativa e houve investigação, notificação e avaliação de sequelas dos casos notificados.

Havia, nesse combate epidêmico, oposição dos defensores de campanhas de rotina, porém o alto índice de redução de casos da doença, por exemplo, de 1290 em 1980 para 122 casos reforçou a política de vacinação em massa, de modo que os dias nacionais de vacinação são implantados até hoje. (CAMPOS, 2003. p. 594-595).

Assim, o modelo de vacinação de rotina perdeu força e foram criados dias nacionais de vacinação, os primeiros em 14 e 16 de agosto de 1980 para que houvesse vacinação em massa em todo o território nacional para crianças entre zero e cinco anos de idade em todo o território nacional, com forte apoio da mídia, que demonstrou que somente em 1975 foram 3500 casos de poliomielite (segundo denúncias do cientista que criou a vacina, Sabin) e que a vacina precisava se conscientizar da importância da vacinação. (CAMPOS, 2003. p. 592)

Então, as campanhas de vacinação adotaram o seu primeiro personagem: o "Dr. Prevenildo", que pedia para que as pessoas procurassem centros de saúde e se prevenissem de doenças com a vacinação, informando que as pessoas que não vacinassem seus filhos até completarem um ano, perderiam o direito ao salário-família. (BENCHIMOL, 2001, p. 320).

Após a criação do Dr. Prevenildo, houve diversas outras campanhas de vacinação no 
país e, finalmente, em 1986, uma nova personagem foi adotada com a publicação do documento A marca de um compromisso: o "Zé Gotinha", que esteve atrelado à campanha contra a poliomielite .(MORAIS JÚNIOR, 2018, p. 13) De acordo com a Fundação Oswaldo Cruz (2019), a personagem também foi utilizada para campanhas contra o sarampo, devido ao seu sucesso com as crianças.

A poliomielite paralítica, graças a alta eficácia dos programas de vacinação, que tinha altas taxas de cobertura, foi considerada erradicada do Brasil em 1994 pela Organização Mundial da Saúde (OMS) (SOARES, 2019, p. 53) e, com essa vitória da saúde e a queda enorme de casos de crianças com paralisia infantil, as vacinas ganharam força e apoio da população a nível universal e não somente para um grupo. (CAMPOS, 2003, p. 597)

O PNI alcançou altas taxas de cobertura, sendo superiores a $95 \%$ do público alvo para todas as vacinas que constavam no calendário de vacinação, com destaque para as vacinas BCG e tríplice viral, que alcançaram percentuais de $100 \%$ ou mais em relação ao público alvo almejado. Vacinas que foram implantadas chegaram a atingir a média de $100 \%$ de cobertura, como a vacina contra o Meningo-C, em 2010. (SVS, 2015, p. 1-13).

$\mathrm{Na}$ época a novidade era o aumento do número de vacinas e que podiam ser conjugadas. Dessa forma, as pessoas poderiam ser imunizadas para mais doenças, com menos injeções e doses. (SVS-MS, 2018, p.1-13). As exceções a essas altas taxas de cobertura eram as vacinas para rotavírus e pneumo 10, com coberturas médias inferiores às estabelecidas, mas apresentavam constante evolução na taxa de cobertura até 2013, o que trouxe, em 2015, muito otimismo em relação ao aumento e cobertura total de vacinas no país.(SVS, 2015, pp. 1-13).

Em relação a vacina da febre amarela, de janeiro de 2004 a dezembro de 2013, houve uma taxa de cobertura de 66\%. Uma taxa que poderia ser maior, pois, em 2008/2009 houve um surto de febre amarela nos Estados da região centro-oeste do país, que intensificaram as vacinações, elevando o número de doses que eram aplicadas de 3,2 milhões para 14,5 milhões, em 2008. (SVS, 2015, p. 1-13).

As principais doenças erradicadas ao longo dos anos no Brasil, graças as campanhas de imunização foram a varíola, febre amarela, sarampo, difteria, tuberculose, tétano maternoneonatal (TMN), coqueluche, poliomielite, rubéola congênita, Meningite por Hib (haemophilus influenzae B). (LEVI, 2019, p. 9-12)

A alta taxa de cobertura e adesão às campanhas vacinais levaram a um outro dado: o aumento da expectativa de vida no país, que deu um salto. Na década de 1940, a expectativa de vida no país era de 45,5 anos , que passou para 75,8 ano em 2016, ou seja, um ganho de 
cerca de 30 anos - para 2100, o Instituto Brasileiro de Geografia e Estatística projetava uma expectativa de 84,3 anos. (IBGE, 2017, p. 9)

Em 2021, a notícia que se tem é que a expectativa de vida do Brasileiro diminuiu 1,3 ano em 2020, e, 1,8 ano em 2021 devido o excesso de mortes provocadas pela Covid-19. De acordo com o IBGE, a expectativa de vida em 2018 era de 76,3 (até 73,1 para homens e 80,1, para mulheres). Em 2019 foi de 76,6 anos. (CASTRO, et. al, 2021, p.1629) De 2021, ainda não se tem dados.

Segundo Castro et. al. (2021, p.1630 ), “o número de mortos de covid-19 no Brasil foi catastrófico. Os ganhos estatuais de longevidade foram revertidos pela pandemia. A falta de uma resposta coordenada, rápida e equitativa informada pela ciência, bem como a promoção da desinformação, têm sido a marca do atual governo". Ainda informou que o resultado do país o fez retroceder aos patamares de 2014 e a queda da expectativa de vida das pessoas a partir de 65 anos retrocedeu aos patamares de 2012. (CASTRO, et. al, 2021, p.1630) Os cientistas ainda afirmam:

Nos primeiros quatro meses de 2021, as mortes de covid-19 representaram $107 \%$ do total de 2020. Supondo que as taxas de mortalidade teriam sido iguais às taxas de todas as causas de 2019 na ausência de covid-19, as mortes de covid-19 em 2021 já reduziram a expectativa $2021 \mathrm{em} \mathrm{1,8}$ ano, o que é ligeiramente maior do que a redução estimada para 2020 em suposições semelhantes. (CASTRO, et. al, 2021, p.1630)

O Brasil está entre os países com maior taxa de mortalidade pela atual pandemia de Covid-19. O crescimento desde o início da pandemia foi exponencial, graças à tardia adoção de medidas profiláticas e a baixa adesão à vacinação. Após, o início da imunização, mesmo com grupos contrários, o país que já chegou a ter em torno de 4 mil mortes diárias, atualmente tem menos de mil mortos por dia e houve, inclusive, desativação de diversos hospitais de campanha que foram criados especificamente para combater a infecção dos brasileiros. (COLLUCCI, 2021)

Mesmo com a possibilidade de imunização, os grupos anti-vacinas permaneceram atuantes, defendendo tratamento precoce com medicamentos sem comprovação científica para a doença. Até aqueles que já haviam se imunizado com a primeira dose da vacina não retornaram para tomar as doses que completavam seu esquema vacinal, fazendo com que os profissionais da saúde tivessem que fazer uma busca ativa desses pacientes em suas casas.

O outro revés, foi a queda brusca na cobertura vacinal de outras doenças do calendário, que fizeram o poder público criar novamente campanhas para adesão destas, gastanto mais tempo, mais dinheiro que deveria ser investido em outras medidas essenciais de 
saúde, apenas para combater à essa desinformação propagada. (COLUCCI, 2021) Essa queda de cobertura vacinal, está intimamente ligada à pós-modernidade, que tem como característica uma nova cultura informacional, como se vê a seguir.

\section{VACINAS VERSUS FAKENEWS}

Atualmente há uma cultura da internet: "um conjunto de valores e crenças que compõem o comportamento. Padrões de comportamento repetitivo geram costumes que são impostos por instituições, bem como por organizações sociais informais". Uma sociedade em rede. (CASTELLS, 2003, p.51). Graças a flexibilidade e o grande poder de comunicação na internet, o individualismo em rede passa a ser um padrão ao invés do acúmulo de pessoas na sociedade, de modo que "as redes on-line, quando se estabilizam em sua prática, podem formar comunidades, comunidades virtuais, diferentes das físicas, mas não necessariamente menos intensas ou menos eficazes na criação de laços e na mobilização. (CASTELLS, 2003, p. 109)

Bauman, (1998, p.10) denomina esse período como pós-modernidade sendo sua característica marcante a busca de "liberdade plena e felicidade irracional contínua", diferente daquele desejo de segurança das gerações passadas. Há, atualmente, um exacerbado hedonismo: "os homens e as mulheres pós-modernos trocaram um quinhão de suas possibilidades de segurança por um quinhão de felicidade. Na modernidade havia uma necessidade de segurança ao invés de uma felicidade individual, já na pós-modernidade, os mal-estares " provêm de uma espécie de liberdade de procura do prazer que tolera uma segurança individual pequena demais. (BAUMAN, 1998, p. 10)

Essa busca incessante pelo prazer torna as pessoas menos propensas a aceitarem a realidade quando essa se mostra contrária aos desejos pessoais $\mathrm{O}$ ambiente da internet facilita o exercício da liberdade de expressão, exteriorizada através da manifestação do pensamento, mas também facilita a circulação e busca da informação, quer seja através de sites de endereços específicos e direcionados, quer seja por buscas genéricas.

A verdade está relacionada ao poder. Sempre que a verdade é contestada, há uma disputa acerca da veracidade ou falsidade de crenças, assim "a disputa é acerca do estabelecimento ou reafirmação das relações de superioridade e inferioridade, de dominação e submissão, entre os detentores de crenças.” (BAUMAN, 1998, p. 144)

O Brasil é um dos países que mais produz falsas notícias na rede. No segundo trimestre de 2018, houve o registro de 63,8 milhões de falsas notícias, caracterizando um 
aumento de $12 \%$ em relação ao primeiro trimestre e um aumento de $95,9 \%$ em relação ao ano de 2017. (DFNDR LAB, 2019) Esses dados são alarmantes, pois em relação aos dados do IBGE sobre a população brasileira, uma a cada três pessoas no país são vítimas de falsas notícias.

O número de notícias falsas retratados, com uma influência sobre a opinião popular foi tão alto nos últimos anos, que organizações foram criadas para combater a desinformação no campo da política, como exemplo a First Draft (EUA, em 2005), que combateu notícias mentirosas nas eleições dos EUA, França, Reino Unido, Alemanha, Brasil e Nigéria. (FIRST DRAFT, 2019) Dados mostram que as eleições que elegeram Donald Trump, nos EUA, foram arraigadas de falsas notícias que influenciaram os eleitores. (FIRST DRAFT, 2019)

No Brasil, a organização apoiou o projeto Com Prova, que atuou durante a campanha eleitoral brasileira (entre setembro e outubro de 2018), seguindo os moldes norte-americanos de campanha sensacionalista, com a união de 24 veículos de informação investigando fake News. (COM PROVA, 2020)

Ao término das eleições, o projeto encerrou suas atividades. Analisando o site do projeto, se verifica o quanto as pessoas estavam realmente acreditando em Fake News, principalmente nas deepfakes, pela quantidade de notícias falsas diárias que chegavam para serem desvendadas pelos colaboradores. O Centro para a Inovação em Governança Internacional afirma que $86 \%$ dos internautas já acreditaram em fake News: “77\% dos usuários do Facebook consultados disseram que viram circular informação total ou parcialmente falsa. Esta cifra cai 62\% entre os usuários do Twitter”. (AFP, 2019).

Andrew Wakefield, em 1998, publicou uma pesquisa na The Lancet, uma das mais relevantes publicações de medicina do Reino Unido, tentando comprovar a relação entre vacina para sarampo, rubéola e caxumba com a incidência de autismo em crianças. Sua teoria, nunca foi aceita pela comunidade científica e se mostrou fraudulenta. Ele teve seu diploma cassado pela justiça, que considerou sua publicação de má fé. (ALLEONI, 2019) Entretanto, até hoje ainda é um grande influenciador anti-vacina, e é considerado um dos grandes culpados pelo surto de sarampo nos anos 90, nos EUA.

Seu artigo ainda causa dúvidas entre as pessoas e, para ajudar na disseminação dessa publicação, pessoas famosas aderiram ao movimento, como Jim Carey, Alicia Silverstone, Erin Broncovich, Charlie Sheen, Robert de Niro, Selma Blair e o ex-presidente Donald Trump que, inclusive, não trouxe modificações nas políticas de imunização do país, mesmo com surtos crescentes de sarampo e, ainda, relacionou as vacinas ao autismo em um tuíte que dizia: 
“Uma criança saudável vai ao médico e leva uma injeção, com muitas vacinas, não se sente bem e muda. AUTISMO. São muitos e muitos casos". (ALLEONI, 2019)

Existe uma forte ação de digitais influencers, que utilizam uma fundamentação pseudocientífica de falsos especialistas de determinados assuntos, para gerar credibilidade aos seus discursos, mesmo que esses não sejam, de fato especialistas. Utilizando um tom completamente alarmista para chamar a atenção dos seus seguidores das mídias digitais, exercendo, assim, um forte apelo mobilizador, sem gerarem desconfiança da veracidade das informações passadas e nem caírem no descrédito já que há uma apropriação e uso estratégico destas informações. (CRUZ JÚNIOR, 2019, p. 282)

Os depoimentos de pessoas que detém o poder através de seu espaço nas mídias de comunicação em massa, é extremamente nocivo para a população, ao ponto do movimento antivacina ter sido listado pela OMS como uma das maiores ameaças à saúde global, um exemplo foi o surto de doenças não vistas há décadas com o sarampo, que havia sido erradicado dos Estados Unidos há vinte anos. (LUISA, 2019).

No Brasil, os ideais antivacinas crescem (segundo um estudo da Faculdade São Leopoldo Mandic com a London School of Hygiene and Tropical Medicine). Os resultados apontam que 4,5\% dos pais se recusam a vacinar suas crianças; 16,5 têm medo ou não acham que seja importante para a saúde dos seus filhos. Entre os pais mais jovens, o índice de insegurança é maior ainda, chega a 23\%". (LUISA, 2019).

O indivíduo com maior propensão a recusar a vacinação seria um pai/mãe solteiro, com menos de 25 anos de idade e baixo grau de instrução (podendo alguém no extremo oposto também hesitar), também foram descritos outros fatores como religião, adeptos da naturopatia/ homeopatia e aqueles que possuem facilidade de acesso à fóruns anti-vacinas na internet. Muitos buscando essas informações baseadas em informações de uma pessoa não qualificada para indicar qualquer ausência ou presença de outros tratamentos. Em relação ao aspecto socioeconômico não há diferença em relação à hesitação em tomar vacinas, estando em todos os extremos socioeconômicos. (BROWN, 2018, p. 1-12)

O maior veículo de difusão de desinformação em relação às vacinas são as mídias sociais, em especial o facebook, por onde pessoas de todo o mundo se conectam e recebem informações direcionadas ao movimento antivacinas, o que propicia uma maior propagação dessa desinformação.(HOFFMAN et. al., p. 2222) Deve haver mecanismos de combate à propagação de desinformação sobre as vacinas nas redes e o combate deve ser igual a forma de disseminação: através de difusão direcionada a esses grupos já que, quem se opõe à 
vacinação deturpa dados e percepção de risco para espalhar suas mensagens pelo facebook, utilizando variados argumentos. (HOFFMAN, 2019, p. 2222)

O London School of Hygiene and Tropical Medicine publicou que os mesmos grupos de trolls e bots que disparavam fakenews durante as eleições dos Estados Unidos compartilhavam notícias falsas acerca de vacinas no Twitter. A saúde é um dos principais alvos de fakenews, de modo que Carlos Graeff Teixeira (2019) "sugere que os cientistas brasileiros acelerem um movimento de divulgação sobre a utilidade das vacinas, com informações científicas sobre os seus benefícios, com mensagens positivas e de esclarecimento, inclusive reverenciando cientistas que já lutaram esta luta, como Oswaldo Cruz". (SBMT, 2019).

Para Adriana Teixeira (2018, p. 30) "talvez uma das maiores diferenças entre o passado e o presente das fake News seja a velocidade com que elas ocupam o lugar da verdade", sendo as fake News muito mais problemáticas no século XXI do que em outros períodos, por exemplo, na idade média, os governantes falavam apenas com os nobres; com a impressão e surgimento das estradas de ferro, as notícias já afetavam mais pessoas; e, com advento da internet, afetam o mundo em grande velocidade. (COSTA, 2018).

Para Jean François Lyotard (1988, p. 99-110), o pós-moderno é uma condição cultural caracterizada por uma crise cultural, filosófica e metafísica de maneira universal: há uma modificação nas posições do saber e da ciência. A ciência vem sendo a maior vítima por ser frequentemente questionada por um discurso a respeito de diversas formas de verdade em relação a diferentes pontos de vista, cada grupo com suas realidades particulares.

Para um cientista, a dúvida surge e, daí então, inicia uma pesquisa para que se encontre as respostas, que podem comprovar ou quebrar paradigmas. Porém, não é o que está acontecendo: quando se prova algo que foge do senso comum, o discurso não é aceito. É como se fugindo do senso comum há mudança nas "regras do jogo", o que não pode ser aceito já que havia um consenso. A crítica é quando a ciência passa a ser conduzida por um poder ordinário desse senso e passa a ser regulada por essa espécie de homeostasia (LYOTARD, 1988. p. 100).

Esse "relativismo cognitivo" da pós-modernidade impõe "um pacto anticomunitário. A realidade passa a ser vista como uma esfera tão elusiva, cheia de meandros, de perspectivas divergentes e de grupos heterogêneos, que a busca pela verdade já não representa mais uma missão prioritária". Desse modo, há abertura para "clubismos", onde as pessoas aderem a esses grupos e depois aos seus discursos, sem críticas em relação as evidências mostradas e 
com propagação destes a todo custo. (CRUZ JÚNIOR, 2019, p. 82)

A pós-verdade tem uma complexa constelação de temáticas, em que se identifica fenômenos como: negacionismo científico, hiperpolarização política, vieses cognitivos, big data, mídias sociais, bolhas on-line e pós-modernidade. (CRUZ JÚNIOR, 2019, p. 82)

As taxas de cobertura vacinais no Brasil tiveram a maior queda em 16 anos no ano de 2018, quando pela primeira vez, todas as vacinas para crianças com menos de um ano ficaram abaixo da meta do Ministério da Saúde, que previa 95\% e tinha índices de mais de $100 \%$ no período. "Entre as vacinas com redução na cobertura estão aquelas que protegem contra a poliomielite, sarampo, caxumba, rubéola, difteria, varicela, rotavírus e meningite”. Atribui-se essa queda às falsas notícias veiculadas em redes sociais, sendo "um movimento inadequado e fantasioso, mas às vezes algumas famílias entram nessas conversas”. (CANCIAN, 2018).

Os índices caíram para 70,7\% a 83,9\%, com exceção da BCG que é ofertada dentro das maternidades, com $91 \%$. Uma queda em torno de 30\%, ou seja, têm-se $30 \%$ de suscetíveis à doenças e, "ter 70\% de cobertura significa ter 30\% de suscetíveis.". (CANCIAN, 2018).

Em 2018, Roraima somou 172 casos confirmados de sarampo, muitos deles em venezuelanos que chegaram ao Brasil devido a crise econômica da Venezuela; 147 casos no AM e 5 no RS. Somente nesses três estados, havia 1.240 casos em investigação. Lembrando que o Brasil havia recebido da Organização Panamericana de Saúde, um certificado de eliminação do sarampo.(CANCIAN, 2018)

Em 2019, sem conseguir conter os casos de sarampo desde 2018, o Brasil perdeu o certificado de eliminação da doença e até esse ano foram o total de 10.326 casos confirmados em 11 Estados Brasileiros. Isso confirma que há um aumento exponencial nos casos da doença graças a disseminação de falsas notícias desde 2015 a respeito da vacina que, desde então, tem uma constante queda nas taxas de cobertura, tendo seu ápice de queda a partir de 2017. (CANCIAN, 2019)

A disseminação dessas falsas notícias em relação às vacinas criou um alerta aos responsáveis pelo programa nacional de imunizações. No site do ministério da saúde há um link desvendando as maiores mentiras divulgadas na rede, com o título Com saúde não se brinca! Diga NÃO às fake News, dentre as quais se inserem as seguintes notícias falsas: a) vacinas causam autismo; b) uma melhor higiene e saneamento farão as doenças desaparecerem - as vacinas não são necessárias; c) as vacinas têm vários efeitos colaterais prejudiciais e de longo prazo que ainda são desconhecidos. A vacinação pode ser até fatal; d) a vacina combinada contra a difteria, tétano e coqueluche e a vacina contra a poliomielite 
causam a síndrome da morte súbita infantil; e) as doenças evitáveis por vacinas estão quase erradicadas em meu país, por isso não há razão para me vacinar; f) doenças infantis evitáveis por vacinas são apenas infelizes fatos da vida; g) aplicar mais de uma vacina ao mesmo tempo em uma criança pode aumentar o risco de eventos adversos prejudiciais, que podem sobrecarregar seu sistema imunológico; h) as vacinas contêm mercúrio, que é perigoso. (MINISTÉRIO DA SAÚDE, 2019)

O boletim epidemiológico publicado pela Secretaria de Saúde de São Paulo, de dezessete de julho de 2019, sobre casos de sarampo, de 1980 até 2019, trouxe dados alarmantes: em 2016 e 2017, nenhum caso foi reportado, em 2018 houveram 5 casos de Sarampo no Estado, e, em 2019 houveram 484 casos até a data da coleta, o que equivaleria a um coeficiente de 1,17 em cem mil habitantes e um aumento de quase $800 \%$.

O Governo Federal em Janeiro de 2019, registrou em torno de 10,2 casos de Sarampo, principalmente no Amazonas e em Roraima, que atribuem à imigração de Venezuelanos que podem ter trazido o vírus, que o governo afirma ter o genótipo muito parecido com o encontrado nos Estados brasileiros. (BRASIL, 2019)

São Paulo sempre obteve taxas de vacinação acima de 95\% para o Sarampo, porem, a campanha de 2019 teve baixa adesão e foi necessário se criar o Dia D para a vacinação de pessoas até 29 anos, realizado em julho. Através de dados coletados pelos responsáveis pelo programa Nacional de Imunização, a estimativa da Coordenadoria de Vigilância em Saúde (Covisa) era a de imunizar 2,9 milhões de indivíduos entre os 15 e os 29 anos, porém até o dia 19 de junho, haviam sido vacinadas 12265 mil pessoas. Um número muitíssimo abaixo do preconizado, que seria acima de 95\%. (ALBUQUERQUE, 2019)

O Governo adotou medidas emergenciais, criando campanhas de vacinação em meios de comunicação, justamente pela baixa adesão que atualmente estas vêm enfrentando. Ou seja, não somente estes grupos anti-vacinas estão disseminando informações falsas acerca da efetividade e efeitos colaterais em relação a vacina contra a Covid-19, como essas campanhas também estão trazendo dúvidas quanto às vacinas que sempre foram aplicadas com efetividade em toda a população brasileira.

Uma das medidas sugeridas para que haja uma espécie de incentivo à vacinação é o passaporte da vacina, uma das medidas que visa coibir o acesso de pessoas não vacinadas em ambientes fechados e com número grande de pessoas circulantes.(G1, 2021) Para viagens internacionais, é necessário que se apresente, inclusive, o atestado de imunização contra a covid-19. 
Porém, grupos extremistas, contra a vacinação, se sentem lesados em seu direito à liberdade, como um direito fundamental e da personalidade e que não deve ser tolhido. Por outro lado, pessoas que defendem a imunização em massa para coibir o avanço de Covid-19, são a favor de ter esse "passe da vacina", justamente porque é uma obrigação simples, em prol de um coletivo e totalmente vinculado à sua liberdade de estar nesses locais e tendo resguardado o seu direito à saúde. Desse modo, salutar entender esta questão.

\section{Direito de recusa à vacina, a liberdade e a dignidade humana}

Os direitos fundamentais são aqueles reconhecidos como indispensáveis à pessoa humana, necessários a qualquer um para uma existência digna, livre e igual, mas não basta ao Estado reconhecê-los formalmente. Antes disso, deve buscar concretizá-los, incorporá-los no dia a dia dos cidadãos e de seus agentes. (PINHO, 2002, p. 65)

Estão relacionados com o princípio da dignidade da pessoa humana (art. $1^{\circ}$, III, da Constituição Federal de 1988) e com o princípio da igualdade, conforme disciplina o caput do artigo $5^{\circ}$, onde "todos são iguais perante a lei, sem distinção de qualquer natureza, garantindose aos brasileiros e aos estrangeiros residentes no País a inviolabilidade do direito à vida, à liberdade, à igualdade, à segurança e à propriedade”. (BRASIL, 1988)

A dignidade humana, expressa na Carta Magna, representa um dos pilares do nosso estado democrático de direito e tem como objetivo, garantir que o ser humano seja valorizado através do respeito a um grupo de direitos que deve ser obedecido por todos, incluindo o próprio Estado.

Ao analisar os direitos fundamentais, Adriano de Cupis nos remete à necessidade de existências daqueles para que a dignidade humana possa ser percebida visto que "existem certos direitos sem os quais à personalidade restaria uma susceptibilidade completamente irrealizada, privada de todo o valor concreto: direitos sem os quais os outros direitos subjetivos perderiam o interesse para o indivíduo - o que equivale a dizer que, se eles não existissem, a pessoa não existiria como tal” (CUPIS, 1961, p. 17).

A noção de dignidade repousa na liberdade que o ser humano possui, de ao menos potencialmente, formatar a sua própria existência e ser, portanto, sujeito de direitos conforme traz Ingo Sarlet, arrematando que "já não mais se questiona que a liberdade e os direitos fundamentais inerentes à sua proteção constituem simultaneamente pressuposto e concretização direta da dignidade humana [...] nos parece difícil questionar o entendimento com o qual sem liberdade (negativa ou positiva) não haverá dignidade" (SARLET, 2019, p. 
16).

Por sua vez, Luciana Russo defende que o direito à vida é o direito mais relevante para qualquer ser humano e que a dignidade da pessoa humana é o fundamento da República Federativa do Brasil. E arremata ao dizer que se não houver dignidade não há que se falar em vida (RUSSO, 2009, p. 91).

Pode-se dizer que o artigo $5^{\circ}$, caput da Constituição Federal de 1988, resume o direito à vida como bem maior, prevendo o direito de não ser morto, como também o direito de ter uma vida com dignidade e igualdade perante os demais. Assim, os demais direitos podem ser entendidos como derivados deste direito fundamental.

$\mathrm{O}$ direito à vida é basilar para a dignidade humana. Alexandre de Moraes esclarece que este direito deve se adequar à condição humana, com “alimentação, vestuário, assistência médica-odontológica, educação, cultura, lazer e demais condições vitais”, sendo obrigação do Estado garantir estes direitos, respeitando a cidadania e a dignidade da pessoa humana, com o objetivo de construir uma sociedade livre, justa e solidária. (MORAES, 2003, p.63)

Apesar do direito à vida ser basilar para a existência e o gozo dos demais direitos, este não é absoluto. Assim, nas situações em que um direito individual se confronta com direitos coletivos, torna-se necessário definir o direito de maior valor que terá a tutela jurisdicional. Em particular, o direito de recusar-se a ser vacinado (direito individual) colide com o direito coletivo da saúde que está englobado no direito fundamental à vida.

Neste sentido, o Estado utiliza-se de normas jurídicas para o controle social, já que a função social do Direito inclui garantir o bem-estar da sociedade, ao agir de forma preventiva e não apenas punindo os atos já praticados. Miranda Rosa acrescenta que o direito não serve apenas para resolver conflitos, "ele os previne e vai mais além, pois condiciona, direta ou indiretamente, o comportamento. Sua simples autoridade como forma de manifestação da vontade social, exerce influência da maior significação sobre a conduta grupal”. (ROSA, 2004, p.58)

Assim, é de grande relevância a função educativa que o Direito traz para a sociedade, visto que o fato de existir uma regra passa a percepção de que aquela foi a solução encontrada por aquele grupo, naquele momento, para o bem-estar de todos e o desenvolvimento das relações sociais, assim seguindo o brocardo "dura lex sed lex"(a lei é dura, mas é a lei), pessoas seguem essas normas e adotam comportamentos condizentes a ela, de maneira natural. Isso mostra que a norma jurídica tem grande influência educativa sobre o comportamento social, sendo a que obtém maior eficiência ao dispor de força de 
coação e impor, assim, obediência. (ROSA, 2004, p. 57-58)

Cabe lembrar que a aceitação das normas está conectada à percepção de que as liberdades individuais devem dar lugar ao coletivo para que a sociedade possa crescer de forma ordenada: Essa influência da norma molda as opiniões sociais, através do processo de aprendizado e, posterior, convencimento do que é socialmente útil ou bom e modos de agir dos indivíduos. Então, não se trata, apenas de ameaças, mas, sim, de influência, de modo que, "cuida-se da força condicionante da opinião pessoal e grupal, quanto ao que é justo ou injusto, bom ou mau para a sociedade, modo de proceder adequado ou inadequado".(ROSA, 2004, p. 59)

Mesmo em tempos de paz, o Direito traz soluções administrativas como algumas no Código Civil (BRASIL, 2002) e outras de cunho mais restritivo na área penal e no Código Penal brasileiro (BRASIL, 1940), o capítulo "Dos crimes contra a saúde pública", prevê os crimes de Epidemia (artigo 267) e de infração de medida sanitária preventiva (artigo 268). Na epidemia, pune-se ao agente que propagar germes patogênicos com uma pena de até 15 anos em função da gravidade de seu ato, pelo contágio de outras pessoas, deixando-as em risco de morte.

O Código Civil atribui responsabilidade civil por ato ilícito aquele praticado que ocasiona danos a terceiros, instituindo, como consequência a reparação destes (artigos 186, 187 e 927). (BRASIL, 2002) No entanto, cabe analisar se as medidas previstas para tempos de paz podem ser usadas numa situação de pandemia ou não.

A pandemia é um "Fenômeno patológico que alcança simultaneamente grande número de pessoas em uma zona geográfica muito vasta. Ela difere da epidemia por sua maior dimensão, seja por sua propagação territorial, ou pela gravidade das ocorrências, resultando em número expressivo de casos severos ou mortes (SILVA, 2008, p. 280-283)

Uma pandemia implica em possível restrição de direitos individuais para que os direitos coletivos sejam mantidos e algumas soluções adotadas envolveram isolamento social (quarentena), limitação para viagens, fechamento de algumas fronteiras, proibição de reuniões públicas, suspensão de atividades escolares, industriais como formas de diminuição da propagação do vírus. (referencia)

A adoção de medidas restritivas de direitos necessitam estar amparadas na Constituição Federal, Tratados internacionais de Direitos humanos, levando em consideração o reconhecimento da situação de emergência, estado de exceção ou pandemia, como a que o mundo atualmente enfrenta. 
No Brasil, a Lei no. 13.979/20 veio com várias medidas para enfrentamento da pandemia de COVID-19 (BRASIL, 2020) . No art. $1^{\text {o }}$ deixa claro que as medidas adotadas são para o enfrentamento desta emergência e que o Ministro da saúde vai definir a duração destas, sendo que o prazo estará vinculado ao definido pela OMS. Esta ressalva visava aproveitar a orientação dada pela organização e as medidas com sucesso implementadas em outros países.

Ocorre que algumas associações da sociedade civil se manifestaram de forma contrária à vacinação compulsória., alegando que todos têm o direito de não se vacinar, por uma questão de consciência (art. $5^{\circ}$., VI e VIII), crenças, religião ou pelo receio dos efeitos adversos e não conhecidos das vacinas. Este último tem sido impulsionado pelas fakes news $\underline{\text { sobre vacinação, disseminando muitas inverdades e ajudando a propagar medo na população, }}$ e com isso baixando a cobertura vacinal de várias doenças, sendo algumas delas já consideradas erradicadas.

Nos aspectos de crenças ou filosofia de vida, em 17/12/2020, o Plenário do STF julgou o Agravo ao Recurso Extraordinário 1.267 .879 da ação movida por pais que pretendiam que seus filhos não fossem compulsoriamente vacinados, com base no direito de cada um fazer suas próprias escolhas existenciais. No julgamento do ARE, o relator Min. Luis Barroso deixou clara que a obrigatoriedade da vacinação já existia na Lei no. 6.259/75 (BRASIL, 1975) e na Lei 8.069/90 (BRASIL, 1990) e nessa mesma direção veio a Lei no.13.979/20 (BRASIL, 2020). Em seu voto, o ministro aduz que:

é legítimo impor o caráter compulsório de vacinas que tenha registro em órgão de
vigilância sanitária e em relação à qual exista consenso médico-científico. Diversos
fundamentos justificam a medida, entre os quais: a) o Estado pode, em situações
excepcionais, proteger as pessoas mesmo contra a sua vontade (dignidade como
valor comunitário); b) a vacinação é importante para a proteção de toda a sociedade,
não sendo legítimas escolhas individuais que afetem gravemente direitos de terceiros
(necessidade de imunização coletiva); e c) o poder familiar não autoriza que os pais,
invocando convicção filosófica, coloquem em risco a saúde dos filhos (CF/1988,
arts. 196, 227 e 229) (melhor interesse da criança).

Apesar de não se defender a vacinação forçada, o que deve acontecer é de o comprovante da mesma ser necessário para a "prática de certos atos, como a matrícula de uma criança em escola privada, ou percepção de benefícios, como o Bolsa Família, ou que sejam aplicadas penalidades em caso de descumprimento", ressaltou o Min Luís Barroso.

Assim, o plenário aceitou a tese de repercussão geral e declarou que é "constitucional a obrigatoriedade de imunização por meio de vacina que, registrada em órgão de vigilância sanitária, (i) tenha sido incluída no Programa Nacional de Imunizações, ou (ii) tenha sua aplicação obrigatória determinada em lei”. 
Ainda em 17/12/2020, o plenário julgou a ADI 6586, proposta pelo Partido Democrático Trabalhista, e da ADI 6587, do Partido Trabalhista Brasileiro, ambas arguindo a inconstitucionalidade do art. $3^{\circ}$, III, d, da lei no. 13.979/20 acerca da vacinação compulsória contra a COVID-19.

A decisão sobre ambas ADIs, reforça a necessidade de proteção da coletividade diante dos direitos individuais: "a vacinação em massa da população constitui medida adotada pelas autoridades de saúde pública, com caráter preventivo, apta a reduzir a morbimortalidade de doenças infeciosas transmissíveis e a provocar imunidade de rebanho, com vistas a proteger toda a coletividade, em especial os mais vulneráveis."(grifo nosso).

Ressalta, porém que a vacinação compulsória não significa vacinação à força "por exigir sempre o consentimento do usuário, podendo, contudo, ser implementada por meio de medidas indiretas, as quais compreendem, dentre outras, a restrição ao exercício de certas atividades ou à frequência de determinados lugares". (grifo nosso). Desta forma, o Estado procura-se resguardar o direito à intangibilidade, inviolabilidade e integridade do corpo humano (direito individual) e ao mesmo tempo, "cuidar da saúde e assistência pública" (direito coletivo) como prevê a Constituição Federal, no art. 23, II.

Assim, por decorrência, são constitucionais: a impossibilidade de matricular os filhos em escolas, bem como o impedimento de ingresso em casa de espetáculos ou a específicos locais pela ausência do comprovante de vacinação. Nesta direção, o município de São Paulo através do decreto municipal 60.488/2021, referido como "passaporte da vacina" passou a exigir a apresentação de comprovante de vacinação para ingresso em eventos como shows, feiras, congressos, jogos ou serviço similares onde haja público superior a quinhentas pessoas. Os participantes dos eventos poderão apresentar o "passaporte da vacina" através de aplicativo para celular ou comprovante físico da imunização (SÃO PAULO, 2021).

Por sua vez, a Portaria no. 998/2021 do Tribunal de Justiça do Estado de São Paulo, traz a mesma obrigatoriedade para ingresso nos prédios do Tribunal de Justiça, tendo em vista a necessidade de "preservação da saúde de magistrados, servidores, colaboradores, demais profissionais da área jurídica e do público em geral" visto que "que o interesse público e da sociedade deve prevalecer sobre o interesse particular, notadamente em tempo de grave crise sanitária mundial” conforme declara a Portaria (SÃO PAULO, 2021), referindo-se às decisões quanto à ADI 6.362/DF e ADI 6.586/DF, que autoriza a aplicação de "medidas indiretas, as quais compreendem, dentre outras, a restrição ao exercício de certas atividades ou à frequência de determinados lugares, desde que previstas em lei, ou dela decorrentes". 


\section{CONCLUSÃO}

Levando em consideração todo o histórico do programa nacional de imunizações que já começou encontrando óbices para sua efetividade graças a movimentos contrários, mas que, mesmo assim, conseguiu encontrar bons resultados que levaram à maior adesão que culminou na erradicação de doenças infectocontagiosas e, levando em consideração que a ciência já comprovou, com dados históricos e estatísticos o aumento da expectativa de vida e redução das taxas de mortalidade no país graças ao Programa Nacional de Imunizações;

E, levando em consideração que a sociedade em rede, embora tenha maior disseminação da informação, mas que, por conta do hedonismo característico da pósmodernidade e a possibilidade de formação de grupos virtuais que acabam presos em suas bolhas informacionais que são formadas de acordo com suas convicções pessoais e não derivadas da verdade comprovada pela ciência.

Conclui-se que é o Estado, por meio de medidas legais e jurisdicionais, derivados do sistema de freios e contrapesos característicos da República Federativa do Brasil, que deverá balizar esta coalizão de direitos fundamentais entre a liberdade e o direito à vida, levando em conta justamente esta característica da pós-modernidade, prevalecendo, o direito à vida da coletividade, atribuindo a liberdade mediante um mecanismo condicionante, que é o passaporte da vacina, já que não se pode colocar em risco a vida de todos em detrimento do desejo de liberdade de um grupo, com fundamento nos mesmos fundamentos constitucionais suscitados por ambas as partes..

Desse modo, todos permanecem livres para adentrarem onde quiserem, porém, com o elemento condicionante. Assim, quem não quiser se vacinar, deverá suportar o ônus de não poder adentrar em determinados estabelecimentos, quem quiser ter liberdade de acesso terá que se vacinar. É o modo em que a liberdade de locomoção e de pensamento estarão assegurados, assegurando, também, a saúde de todos, base do direito maior que é o direito fundamental à vida.

\section{REFERÊNCIAS}

AFP. Pesquisa Global revela que $86 \%$ dos internautas já acreditaram em "fake News". Exame, São Paulo, 12 jun. 2019. Disponível em: https://exame.abril.com.br/brasil/pesquisaglobal-revela-que-86-dos-internautas-ja-acreditaram-fakenews/?fbclid=IwAR0z89MpNxFrzryphfA3PaIRfPRp8PpHKqdyUtYcHtlKvSXEx0QpcaUvG Rg. Acesso em: 15 jun. 2019.

ALBUQUERQUE, Flávia. São Paulo terá Dia D de vacinação do sarampo no sábado. Quem 
deve tomar? Saúde, São Paulo, 24 jul. 2019. Disponível em:

https://saude.abril.com.br/medicina/sao-paulo-tera-dia-d-de-vacinacao-do-sarampo-nosabado-quem-deve-tomar/. Acesso em: 30 jul. 2019.

ALLEONI, Matheus. Fake news das antigas, movimento antivacina segue com força nas redes sociais. São Paulo, 1 jan. 2019. Saúde. Disponível em: https://saude.ig.com.br/2019-0113/movimento-antivacina-anti-vaxxers.html. Acesso em: 19 jun. 2019.

BAUMAN, Zygmunt. O mal-estar da pós-modernidade. Rio de Janeiro: Zahar. 1998.

BENCHIMOL, Jaime Larry. Febre Amarela: a doença, a vacina, uma história inacabada. Rio de Janeiro: Fiocruz, 2001. Disponível em:

https://www.academia.edu/31905780/FEBRE_AMARELA_A_DOEN\%C3\%87A_E_A_VAC INA_UMA_HIST\%C3\%93RIA_INACABADA. Acesso em: 12 jun. 2019.

BRASIL. Casos de sarampo chegam a 10,2 mil: Ministério da Saúde investe em vacinação, capacitação e apoio técnico para conter surtos no Amazonas e em Roraima. 9 jan. 2019.

Disponível em: http://www.brasil.gov.br/noticias/saude/2019/01/casos-de-sarampo-chegam-a10-2-mil. Acesso em: 30 jul. 2019.

BRASIL. Código Civil Brasileiro. Lei no. 10.406/2002. 2002.

BRASIL. Código Penal Brasileiro. Decreto-Lei no. 2.848. 1940.

BRASIL. Constituição Federal da República Federativa do Brasil. 1988.

BRASIL. Lei n. 6.259/ 1975. Dispõe sobre a organização das ações de Vigilância Epidemiológica, sobre o Programa Nacional de Imunizações, estabelece normas relativas à notificação compulsória de doenças, e dá outras providências. 1975.

BRASIL. Lei 8.069. Dispõe sobre o Estatuto da Criança e do Adolescente e dá outras providências.1990a.

BRASIL. Lei 8.080/1990. Dispõe sobre as condições para a promoção, proteção e recuperação da saúde, a organização e o funcionamento dos serviços correspondentes e dá outras providências. $1990 \mathrm{~b}$.

BRASIL. Lei 13.979/20. Dispõe sobre as medidas para enfrentamento da emergência de saúde pública de importância internacional decorrente do coronavírus responsável pelo surto de 2019. 2020.

BRASIL. Secretaria de vigilância em saúde /SVS- MS. Programa Nacional de Imunizações: Aspectos históricos dos calendários de vacinação e avanços dos indicadores de coberturas vacinais, no período de 1980 a 2013. Boletim Epidemiológico, Brasília, v. 46, n. 30, p.1-13. 2015.

BROWN, Amy Louise et. al. Vaccine confidence and hesitancy in Brazil. Cadernos de Saúde Pública/ Reports in Public Health, São Paulo, n. 34, p. 1-12, 18 abr. 2018. Disponível em: http://www.scielo.br/pdf/csp/v34n9/1678-4464-csp-34-09-e00011618.pdf. Acesso em: 17 jun. 2019.

CAMPOS, André Luiz Vieira de; NASCIMENTO, Dilene Raimundo do; MARANHÃO, Eduardo. A história da poliomielite no Brasil e seu controle por imunização. História, Ciências e Saúde - Manguinhos. Rio de Janeiro, v.10, p. 573-600. 2003. Disponível em: http://www.scielo.br/pdf/\%0D/hcsm/v10s2/a07v10s2.pdf. Acesso em: 13 jun. 2019.

CASTELLS, Manuel. A Galáxia da Internet: Reflexões sobre a Internet, os negócios e a sociedade. Rio de Janeiro: Jorge Zahar Editor, 2003.

CANCIAN, Natália. Com registro de novo caso, Brasil perderá status de país livre do sarampo. Folha de São Paulo, São Paulo, 19 mar. 2019. Cotidiano. Disponível em: 
https://www1.folha.uol.com.br/cotidiano/2019/03/apos-novo-caso-brasil-perdera-status-depais-livre-do-sarampo.shtml. Acesso em: 15 jun. 2019.

CANCIAN, Natália. Vacinação de crianças no país atinge índice mais baixo em 16 anos.

Folha de São Paulo, São Paulo, 19 jun. 2018. Cotidiano. Disponível em:

https://www1.folha.uol.com.br/cotidiano/2018/06/vacinacao-de-criancas-no-pais-atingeindice-mais-baixo-em-16-anos.shtml. Acesso em: 15 jun. 2019.

COLLUCCI. Com pandemia, taxa de cobertura vacinal no país despenca e abre brecha para novos surtos. Folha de São Paulo. São Paulo, 03 jun. 2021. Coronavírus. Disponível em: https://www1.folha.uol.com.br/equilibrioesaude/2021/06/com-pandemia-taxa-de-coberturavacinal-no-pais-despenca-e-abre-brecha-para-novos-surtos.shtml. Acesso em: 02 out. 2021.

COSTA, Camila. 'Perigo de notícias falsas e mentiras é maior hoje do que jamais foi', diz historiador britânico. BBC News Brasil, São Paulo, 11 ago. 2018. Internacional. Disponível em: https://www.bbc.com/portuguese/geral-45090376. Acesso em: 14 jun. 2019.

CRUZ JÚNIOR, Gison. Pós-verdade: A nova guerra contra os fatos em tempos de fake News. ETD- Educação Digital, v. 21. p. 278-284, jan/mar. 2019. p. 282.

CUPIS, Adriano de. Os direitos da personalidade. Lisboa: Livraria Morais, 1961.

DFNDR LAB. Relatório da Segurança digital no Brasil. Disponível em:

https://www.psafe.com/dfndr-lab/wp-content/uploads/2018/08/Relatório-da-Segurança-

Digital-no-Brasil-2-trimestre-2018.pdf. Acesso em: 19 jun. 2019.

DICTIONARY.COM. Dictionary.com's 2018 Word Of The Year Is Misinformation.

Disponível em: https://www.dictionary.com/e/word-of-the-year/. Acesso em 15 jun. 2019.

FUNDAÇÃO OSWALDO CRUZ. Zé Gotinha. Instituto de Tecnologia em imunobiológicos - Bio-Manguinhos. Disponível em: https://www.bio.fiocruz.br/index.php/123-clubinho-debio/ze-gotinha. Acesso em: 14 jun. 2019.

G1.Cidade de SP passa a exigir comprovante de vacinação para entrada em eventos com mais de 500 pessoas a partir desta quarta. G1. São Paulo, 01 set. 2021. Disponível em: https://g1.globo.com/sp/sao-paulo/noticia/2021/09/01/cidade-de-sp-passa-a-exigircomprovante-de-vacinacao-para-entrada-em-eventos-com-mais-de-500-pessoas-a-partirdesta-quarta.ghtml. Acesso em: 03 out. 2021.

HOFFMAN, Beth L. et. al. It's not all about autism: the emerging landscape of antivaccination sentiment on facebook. Vaccine, Pittsburgh - United States, n. 37, p. 2216-2223. 6 mar. 2019.

IBGE. Tábua completa de mortalidade para o Brasil - 2017. Disponível em: https://biblioteca.ibge.gov.br/visualizacao/livros/liv101628.pdf. Acesso em: 14 jun. 2019.

LEVI, Guido Carlos; LEVI, Mônica. Vacinação: estratégia que mudou o cenário de saúde no Brasil. Revista Imunizações, São Paulo, mar. 2019. Artigo Original, p. 9-12. Disponível em: https://sbim.org.br/images/revistas/revista-imuniz-sbim-v12-n1-2019.pdf. Acesso em: 14 jun. 2019.

LUISA, Ingrid. Cresce a desconfiança com vacinas no Brasil, diz estudo. Revista superinteressante, São Paulo, 7 jun. 2019. Saúde. Disponível em:

https://super.abril.com.br/saude/165-dos-pais-brasileiros-tem-receio-de-vacinar-osfilhos/?fbclid=IwAR1RoioiFngO3zqbgJdhsRfYaQwKGStX5yjLa4mf-V-

O6NPgLAdv_GHRA0E. Acesso em: 17 jun. 2019.

MINISTÉRIO DA SAÚDE. Calendário Nacional de Vacinação - 2019. Disponível em: https://saude.es.gov.br/Media/sesa/Vacina\%C3\%A7\%C3\%A3o/Calendario\%20Nacional\%20 de\%20Vacinacao\%20-\%202019\%20-\%20POP.pdf. Acesso em: 14 jun. 2019.

MINISTÉRIO DA SAÚDE. Com saúde não se brinca! Diga NÃO às fake News. 
Disponível em: http://www.saude.gov.br/saude-de-a-z/vacinacao/vacine-se\#calendario. Acesso em: 17 jun. 2019.

MORAES, Alexandre. Direito Constitucional. 13 ed. São Paulo: Editora Atlas S.A., 2003. MORAIS JÚNIOR, Sérgio Luis Alves de. et. Al. A evolução histórica do calendário vacinal brasileiro infantil. Revista Enfermagem Atual, Rio de Janeiro, v. 18, n.85, p. 71-75. 2018. PINHO, Rodrigo César Rebello. Teoria geral da Constituição e direitos fundamentais. 3.ed. rev. São Paulo: Saraiva, 2002.

ROSA, Felipe Augusto de Miranda. Sociologia do Direito: o fenômeno jurídico como fato social. 17.ed. Rio de Janeiro: Jorge Zahar Ed., 2004

RUSSO, Luciana. Direito Constitucional. $2^{\text {a }}$ Ed. São Paulo: Editora Saraiva, 2009.

SÃO PAULO. Tribunal de Justiça. Portaria n ${ }^{\circ}$ 9998/2021.

SÃO PAULO. Decreto $n^{\circ} 60.488$. Dispões sobre a instituição do passaporte da vacina e estabelece a sua exigência para acesso a estabelecimentos. 2021.

SARLET, Ingo Wolfgang. Dignidade (da pessoa) humana e direitos fundamentais na Constituição Federal de 1988. 10 ed. Porto Alegre: Livraria do Advogado, 2019.

SILVA, Marcelo. Revista de Direito Sanitário, v. 9, Centro de Estudos e Pesquisas de Direito Sanitário. São Paulo. 2008.

SOCIEDADE BRASILEIRA DE MEDICINA TROPICAL. Movimento antivacina é uma das dez ameaças para a saúde mundial. 11 abr. 2019. Disponível em:

https://www.sbmt.org.br/portal/anti-vaccine-movement-is-one-of-the-ten-threats-to-globalhealth/. Acesso em: 16 jun. 2019.

TEIXEIRA, Adriana. Fake News contra a vida: desinformação ameaça vacinação de combate à febre amarela. 2018. Dissertação (Mestrado em Comunicação em Fisiopatologia experimental)- Pontifícia Universidade Católica, PUC-SP, São Paulo, 2018.

TEMPORÃO, J. G.: 'O Programa Nacional de Imunizações (PNI): origens e desenvolvimento'. História, Ciências, Saúde Manguinhos, vol. 10 (suplemento 2): 601-17, 2003. Disponível em: http://www.scielo.br/pdf/hcsm/v10s2/a08v10s2.pdf. Acesso em: 12 jun. 2019. 